Department of Clinical Neuroscience

Poyan Karimi

Study Program in Medicine KI

Degree project 30 credits

Fall 2019

\title{
A functional magnetic resonance imaging study on sleep deprivation and its effect on empathy for pain and emotional regulation
}

Part of the Stockholm Sleepy Brain Project 3

Final version 17/1-2020

Author: Poyan Karimi 


\section{Effekten av sömnbrist på empati och emotionell reglering undersökt med funktionell magnetkamera teknik}

Bakgrund: Empati och emotionell reglering anses viktiga i sociala interaktioner. Effekten av sömnbrist på empatisk förmåga och emotionell reglering har inte undersökts med funktionella mått. Tidigare forskning som använt partiell sömndeprivering har inte kunnat påvisa några signifikanta fynd. Syfte: Syftet med studien var att undersöka hur total sömnbrist påverkar empati för smärta hos andra och emotionell reglering genom självskattat obehag och fMRI aktivitet i förutbestämda områden. Material och Metoder: I en överkorsad design omfattande en natt av total sömnbrist och en natt med full sömn fick 18 friska unga deltagare instruktioner om att nedreglera eller bibehålla sin emotionella respons gentemot 48 bilder av händer eller fötter i smärtsamma situationer eller icke-smärtsamma situationer följt av skattningar på upplevt obehag, samtidigt som funktionella bilder togs. Resultat: Skattningar av obehag visade en signifikant ökning mellan obehagliga och neutrala bilder $(13.4$ [11.6 - 15.2], $p<$ 0.00001) och en signifikant minskning sågs vid interaktionen sömndeprivering och obehagliga bilder (4.8 [-8.34 - -1.25], $p=0.0079)$. För funktionella mått sågs en signifikant ökat aktivering i anteriora midcingulära kortex $(\mathrm{T}=2.52[0.17-2.18], p<0.024)$ när effekten av smärtsamma och icke-smärtsamma bilder jämfördes. Inga signifikanta funktionella resultat sågs $\mathrm{i}$ anteriora insula, lateroorbitofrontala kortex, anteriora midcingulära kortex eller dorsolaterala prefrontalkortex när betingelserna full sömn och total sömnbrist jämfördes. Slutsats: Studien indikerar att sömnbrist leder till minskad subjektiv empati gentemot andra i smärtsamma situationer, dock utan funktionella korrelat. Framtida studier borde kombinera fullständig sömndeprivering med högre antal deltagare.

\section{A functional magnetic resonance imaging study on sleep deprivation and its effect on empathy for pain and emotional regulation}

Introduction: Empathy and emotional regulation are considered important in social interactions. The relationship between sleep and higher order neurological functions connected to social interactions is poorly understood and results have been inconclusive. Aims: The aim of this study was to investigate how total sleep deprivation affects empathy for pain in others and emotional regulation through selfrated unpleasantness scores and fMRI activity in predetermined regions of interest. Material and Methods: In a cross over design with one night of total sleep deprivation and one night of full sleep, 18 healthy young participants were instructed to downregulate or maintain emotional response to 48 images of hands or feet in painful or non-painful situations followed by ratings of unpleasantness on a scale from 0-100, while functional images were acquired. Results: Unpleasantness scores showed a significant increase when comparing pain to no-pain stimuli $(13.4[11.6-15.2], p<0.00001)$ and a significant decrease in unpleasantness from pain stimuli following sleep deprivation (-4.8 [-8.34 - 1.25], $p=0.0079$ ). fMRI results demonstrated a significant increase when comparing pain vs no-pain stimuli in the anterior midcingulate cortex $(\mathrm{T}=2.52[0.17-2.18], p<0.024)$ as expected. No significant functional outcomes were seen in the anterior insula, lateral orbitofrontal cortex, anterior midcingulate cortex or dorsolateral prefrontal cortex when comparing the full sleep to the sleep deprived condition. Conclusions: This study indicate that sleep deprivation causes less subjective empathy for pain in others, however without functional correlates. Future studies should combine larger sample sizes with total sleep deprivation interventions.

Keywords: Sleep deprivation, empathy, emotional regulation, fMRI, rated unpleasantness. 

Abbreviations
$\mathrm{AI}=$ Anterior Insula
$\mathrm{aMCC}=$ Anterior midcingulate cortex
BOLD $=$ Blood-oxygen-level dependent signal
$\mathrm{d} \mathrm{PPFC}=$ Dorsolateral prefrontal cortex
HADS-D = Hospital anxiety and depression score - Depression subscale
ISI = Insomnia severity index
$1 \mathrm{OFC}=$ lateral orbitofrontal cortex
ROI $=$ Region of interest 


\section{Introduction}

Rapid eye movement and non-rapid eye movement sleep as present in humans are found in all studied mammals and even birds (1). Rats that were exposed to extended total sleep deprivation demonstrated several reactions including drastic weight loss and shedding of skin and ultimately died in such experiments, suggesting that sleep is a vital function (2). Other studies implicate that 7-8 hours is the sleep duration associated with lowest mortality in humans (3). It is estimated that a third of the American population gets $\leq 6$ hours of sleep every 24 hours (4). Prolonged sleep deprivation or disturbances in circadian rhythm in humans are associated with increased risk of a variety of somatic diseases including cardiovascular disease, metabolic disease and cancer (5). Prolonged sleep deprivation has also been shown to correlate with a number of psychiatric disorders such as depression, anxiety and mood disorders (6). However, the relation between sleep and higher order neurological functions connected to social interactions is poorly understood and results have been inconclusive (7). Two higher order neurological functions are empathy and emotional regulation which are considered to be important in social situations and professions involving human interaction. Many professions involve irregular working hours which is correlated with impaired sleep. The effect of sleep deprivation on empathy and emotional regulation has not been well studied using functional measurements.

\section{Empathy}

Empathy can, according to Vignemont et al (8), be defined in many different ways but are generally put into two major categories, broad definitions and narrow definitions. Broader definitions such as "an affective response more appropriate to another's situation than one's own" (9) allow the inclusion of related concepts such as sympathy and personal distress. In order to avoid this a more narrow definition is used in this study. According to Vignemont et al (8) a more narrow definition that could be used is the following:

"There is empathy if: (i) one is in an affective state; (ii) this state is isomorphic to another person's affective state; (iii) this state is elicited by the observation or imagination of another person's affective state; (iv) one knows that the other person is the source of one's own affective state." 
The second condition in the definition above emphasizes what is considered to be one important component in empathy, namely shared emotions (10). According to multiple studies, seeing another person in pain causes a bilateral activation of the anterior insula (AI) and the anterior midcingulate cortex (aMCC) and generates a subjective emotional response in the observer (10)(11). The subjective emotional response can be measured using self-rated unpleasantness graded by the observer after being exposed to pictures of others in painful situations.

\section{Emotional regulation through reappraisal}

Emotional regulation has previously been researched and according to Ochsner et al (12) the following techniques may be applied: situation modification, attentional deployment, cognitive reappraisal and response modulation. Situation modification and attentional deployment are described as distraction techniques in which the subject alters the situation or shift focus in order to avoid the emotional stimuli. Response modulation is described as the ability to control one's external response to certain stimuli without altering the internal emotional response. Emotional reappraisal is described as revaluing and modifying the emotional meaning of a stimulus. According to Ochsner et al (12), emotional reappraisal is the most systematically studied technique for several reasons. Emotional reappraisal is relatively easy to measure with functional magnetic resonance imaging (fMRI) since it is easily applicable in immobile settings and it is considered to be the neurologically most complex form of emotional regulation. This complexity is considered by Ochsner et al (12) to be a positive feature since a scientific model able to explain this level of emotional regulation is assumed to be applicable to neurologically less complex forms of emotional regulation such as distraction techniques. Emotional reappraisal has been shown to have a number of positive effects on wellbeing including but not limited to positive effects on life satisfaction and depression (13). Dorsolateral prefrontal cortex (dlPFC) and lateral orbitofrontal cortex (1OFC) have emerged as key areas in emotional regulation according to several meta analyses (14)(12). However, the relationship between sleep impairment and functional measurements of emotional reappraisal is not fully understood. 


\section{Blood-oxygen-level dependent signal (BOLD)}

BOLD is a well-established way of measuring regional brain activity with fMRI. BOLD signal is based on differences in magnetic properties of oxygenated and deoxygenated hemoglobin and levels of cerebral blood flow which correlate with neuronal activity in the brain. In short, increased levels of oxygenated hemoglobin to an area will cause a shift in the magnetic field which is detectable with fMRI (15).

\section{Previous studies and results}

\section{Emotional reappraisal}

The Stockholm Sleepy Brain Project at Karolinska Institutet and Stockholm University is a multimodal brain imaging study on sleep deprivation conducted in several sessions using functional measurements. In a recent study as a part of the Stockholm Sleepy Brain Project Tamm et al. (16) investigated the impact of 3 hours sleep restriction compared to a full night sleep on emotional regulation through emotional reappraisal and measured the effects on the dorsolateral prefrontal cortex (dIPFC), lateral orbitofrontal cortex (IOFC) and amygdala using fMRI and BOLD signaling. The primary hypothesis was that the amygdala would be stimulated by negative stimuli and that the dIPFC and IOFC would excerpt a top-down inhibitory regulation of the amygdala when participants were asked to downregulate their emotional response, and that this functional connectivity would be reduced during sleep deprivation, as suggested in previous research by Yoo et al (17). The fMRI results from Tamm et al. (16) did not show a significant correlation between partial sleep deprivation and reduced activity in the dIPFC or lOFC when performing the emotional reappraisal task. In the same study the effect of partial sleep deprivation on emotional regulation was measured using self-rated unpleasantness scores. No significant outcomes were seen in analyses comparing the sleep deprived condition to the full sleep condition.

\section{Empathic response}

In another study by Tamm et al (19) empathy for pain was measured using fMRI focusing on the anterior midcingulate cortex (aMCC) and anterior insula (AI), areas shown to have a stronger association with empathy for pain than the amygdala (11)(10). In this study too, no significant functional differences could be measured with 3 hours of sleep restriction. Tamm et al (19) showed however that pain stimuli activated the AI bilaterally and the aMCC as expected (20) and a borderline significance was seen when comparing self-rated unpleasantness scores 
indicating a decrease in unpleasantness scores in relation to all stimuli after a night of partial sleep deprivation. No other study has investigated the impact of sleep deprivation on functional aspects of empathic response.

In short the effect of sleep deprivation on empathy and emotional regulation has not been well studied using functional measurements and the previous research has been contradictory. One explanation as to why both studies by Tamm et al (16)(19) mentioned above did not find significant outcomes in the analyses comparing sleep deprived to full sleep condition could be that a 3 hour sleep restriction was not enough to cause a significant outcome and it is suggested that a more distinct sleep deprivation regime might be required in future research (16)(19). As a result this study was designed using fMRI focusing on aMCC and AI as centers of empathy for pain and IOFC and dIPFC as centers of emotional reappraisal combined with self-rated unpleasantness scores with one night of total sleep deprivation, as part of the Stockholm Sleepy Brain Project 3.

\section{Hypotheses}

From the fMRI point of view the expected effect was that pain stimulation would be associated with activity in the AI and aMCC. It was to be investigated whether or not downregulation was associated with activation of the dlPFC and lOFC. Regarding self-assessments scores the hypotheses were that seeing pictures of others in painful situations would cause higher rated unpleasantness, sleep deprivation would cause higher rated unpleasantness and downregulation of the emotional response to pictures of others in painful situations would cause lower rated unpleasantness.

\footnotetext{
Aims

The aim of this study was to investigate how sleep deprivation affects empathy for pain and emotional regulation through self-rated unpleasantness scores and fMRI activity in the AI, aMCC, dlPFC and lOFC.
} 


\section{Materials and Methods}

\section{Participants}

18 healthy young participants as described in the inclusion criteria below were recruited by poster advertising at campus sites in the Stockholm area and at Karolinska Institutet's website for prospective participants. An online form was filled to confirm inclusion/exclusion criteria. In order to determine traits like psychopathy and empathy the Interpersonal reactivity index (22) and Psychopathic Personality Inventory-Revised (23) were used. Positive And Negative Affect Schedule (24) and State-Trait Anxiety Inventory (25) were used to characterize participants' emotional states and anxiety. Written information and consent to use and store images and blood samples taken were collected before the first scan.

\section{Inclusion criteria}

Participants were required to be 20-30 years old, right-handed, fluent in the Swedish language, have good visual acuity and go to bed between 22 and 01 on weekdays. In Tamm et al (16) and Tamm et al (19) older participants (age 50-65) were included but they had trouble following instructions in the fMRI scanner and some of their data could not be used for analysis, hence the younger age interval. Glasses cannot be brought in to the MR scanner which is why good visual acuity is required. Irregular sleeping habits among participants may result in less coherent data and motivates a set circadian rhythm.

\section{Exclusion criteria}

Participants had reside within Stockholm county because of logistical reasons. Previous or current neurological or psychiatric illness as diagnosed by a doctor can intervene with the results in ways that is not yet understood, hence part of exclusion criteria. Students of medicine, psychology, behavioral science or nursing were excluded since these students might try to foresee the expected results of the study and therefore change their responses. Participants had to avoid daily use of nicotine and $>4$ cups of coffee/day ( 1 cup tea $=0,5$ cup coffee, 1 coca cola $=1 / 3$ cup coffee) since this might interfere with sleep. Participants with metal objects in the body were excluded for MR safety and color-blind participants were excluded since it makes instructions harder. Diabetes and hypertonia might cause changes in cerebral blood flow and psycho active drugs or immune modulating drugs are known to interfere with sleeping patterns, hence part of exclusion criteria. Claustrophobic participants were excluded for MR safety. Hospital Anxiety and Depression Scale (HADS-D) >= 8 and Insomnia severity index (ISI) $>=$ 
15 were also part of exclusion criteria since depression and insomnia interferes with sleep. A flowchart of participants is presented in figure 1.

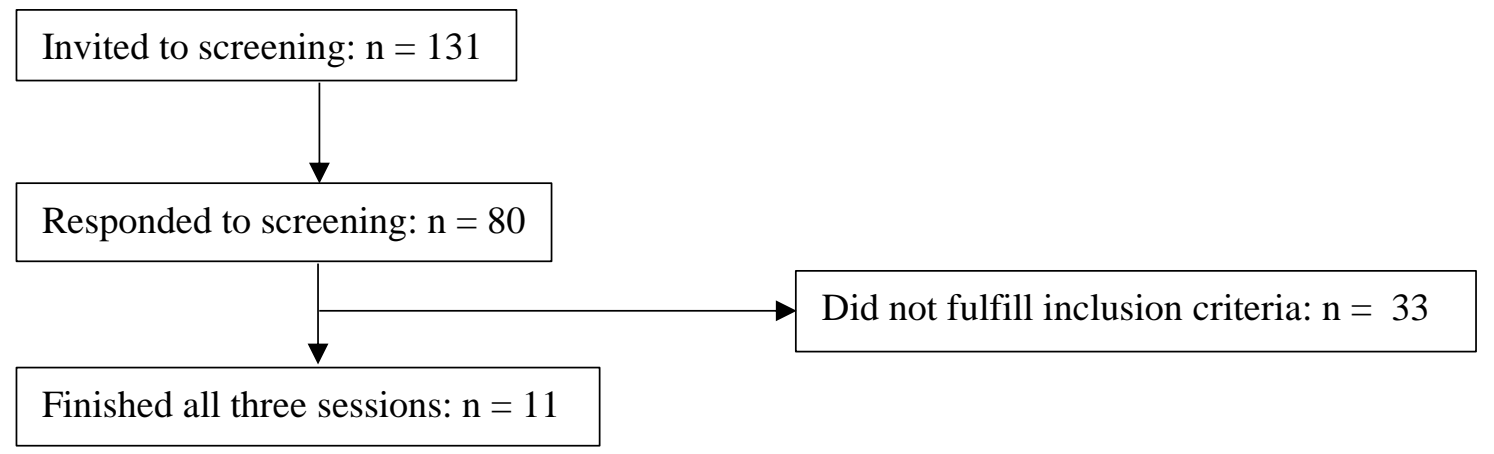

Figure 1: Flowchart of participants in the Stockholm Sleepy Brain 3 project.

\section{Experimental design and procedures}

Participants underwent three sessions in the MR scanner. On the first occasion anatomical pictures were taken. Then there was a cross over design in two blocks in which participants underwent one night of total sleep deprivation surveyed in a sleep laboratory and one night of full sleep conducted at home using a sleep diary. The sleep lab is located at Stockholm university in which a light room was used in order to facilitate keeping participants awake. Participants were allowed to go out for walks and eat, drink, watch movies, work, exercise etc during the intervention night and was always surveyed by at least one of the staff members in order to make sure that no participant fell asleep. No intake of caffeine was allowed during the intervention night. Participants performed the empathy and emotional regulation task in the MR scanner between 7:30 and 9:30 the morning following the sleep deprived and full sleep night respectively.

Data from the Stockholm Sleepy Brain 2 pilot study that was conducted between November 2018 and March 2019 were included in the statistical analyses. In the Stockholm Sleepy Brain 2 experiment an actigraph and sleep diary was used to monitor sleep during the intervention night instead of using the sleep lab. Differences in participant characteristics are presented in the results section. Apart from these differences the Stockholm Sleepy Brain 2 experiment was performed in the same way as Stockholm Sleepy Brain 3 experiment as described above and below. Data from 7 participants were received and analyzed from the Stockholm Sleepy Brain 2 pilot experiment. 


\section{Experimental paradigm}

The experimental paradigm consisted of an instruction to maintain or downregulate the emotional experience, followed by an image of another person's hand or foot in a painful or nonpainful situation, shown for $5 \mathrm{~s}$, followed by an interval of $2 \mathrm{~s}$, and then a rating of unpleasantness on a scale of 0-100 with the cursor starting at 50. All the information was portrayed on a screen in the MR apparatus. fMRI pictures were taken continuously while performing the task. The participants held a console with four buttons in their right hand and used these buttons to perform the experiments. The images have been previously used by Jackson et al. (26) and Decety et al. (27). In total 48 pictures were shown, 16 with the combination maintain and pain, 16 with the combination downregulate and pain and 16 with the combination maintain and no-pain. The task was completed in approximately 14 minutes. The Karolinska sleepiness score (28) was answered right before and right after the 13 minute task. A schematic picture of the experimental paradigm is presented in figure 2 .

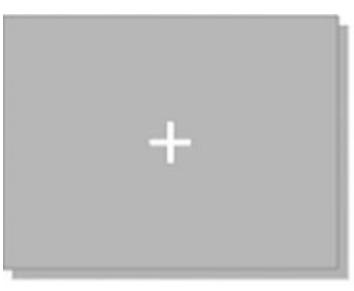

fixation: 4-6 s jitter
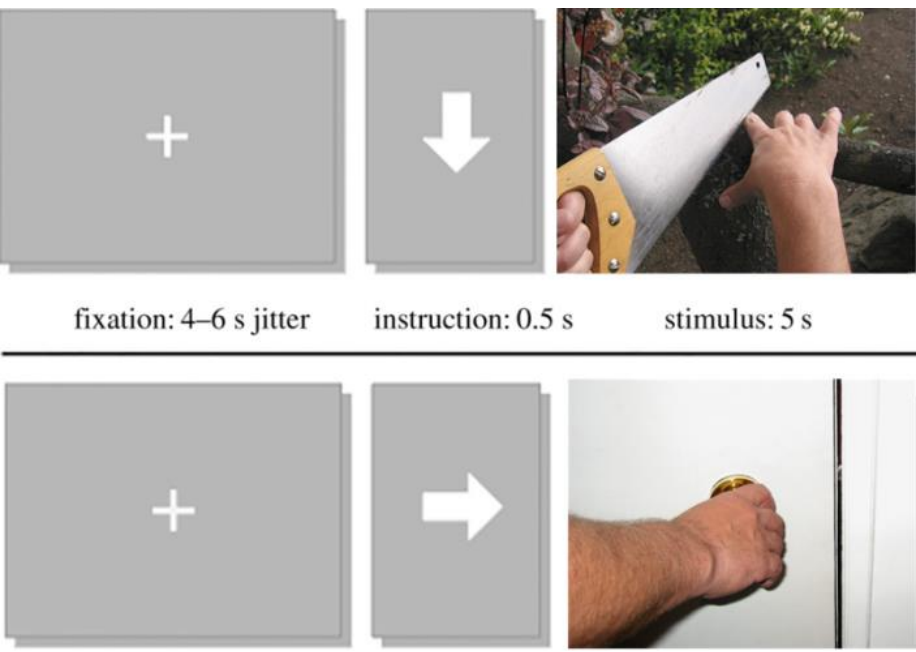

instruction: $0.5 \mathrm{~s}$

stimulus: $5 \mathrm{~s}$
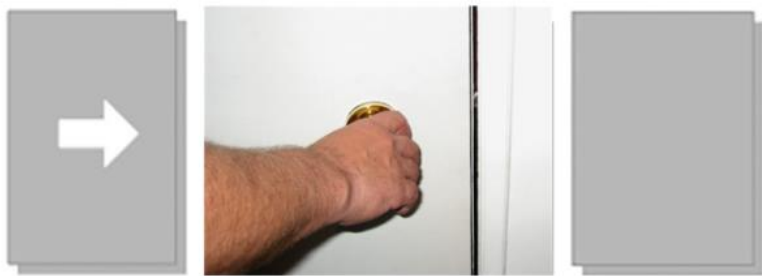

Figure 2: Schematic view of the fMRI task. 


\section{MR scanning}

Structural MR images was acquired using a T1-weighted scan with axial scull plane, flip angel 12 degrees and 180 slices. These images were used for normalization. fMRI images were acquired using the following settings: interleaved acquisition with 40 slices with a thickness of $3 \mathrm{~mm}$, a spacing of $0.5 \mathrm{~mm}$ and a repetition time of 2 seconds. Functional images were preprocessed using a standardized pipeline including slice time correction, realignment, coregistration, normalization, and smoothing, as implemented in the fmriprep software.

\section{Quality control of MRI images}

MRIqc was used and co-registration and normalization was checked to be within reasonable parameters. Head movements was investigated through framewise displacement. Field of view was manually controlled and pictures were examined to exclude possible artefacts. The signal from each tissue compartment and per voxel was examined.

\section{Statistical methods}

Ratings of unpleasantness were analyzed using a mixed-effects model, in order to account for repeated measurements within participants. Rated unpleasantness was regressed on stimulus type (pain/no pain), instruction (maintain/downregulate), and sleep deprivation condition (full sleep/sleep deprivation), with participant ID as a random effect. Statistical tests were performed using the nlme package (29) in $\mathrm{R}(30)$. A p value of $<0.05$ was considered significant.

fMRI data was analyzed using the general linear model. For each run t-contrasts were generated for main effects: pain vs no pain and downregulate vs maintain ( $1_{\text {st }}$ level). T-maps from 1 st level were entered into a factorial design to estimate main effects and the effect of sleep deprivation. Whole brain t-maps were generated and inspected. Effects were analyzed in predetermined regions of interest (ROI). Regions of interest were selected based on earlier studies (19)(16). 


\section{Ethical considerations}

Participants were not expected to be physically or mentally harmed by taking part in this study. Participation was voluntary and all participants were informed that they could withdraw at any time without any explanation. Participants might have been claustrophobic or might have gotten harmed physically in the MRI apparatus if they had metal objects in their body. This was avoided by the exclusion criteria which were doublechecked upon arrival at the first session before entering the MRI. Benign or malignant findings in the MR of medical relevance might either have been good for the participants, with early diagnosis and treatment, or it may have caused unnecessary anxiety while waiting for a benign answer. The risk for this was considered low. A neuroradiologist examined all anatomical images. If any suspicious findings occurred, patients were notified and followed up. It might also have been dangerous for participants to drive to and from the MRI sessions on the day following the sleep deprived night, therefore they were offered taxi service on that day. The participants received $1500 \mathrm{kr}$ for their participation in the study. There is possibly a large impact of sleep deprivation on empathy and emotional regulation resulting in decreased life satisfaction, social impairment and increases in mood disorders. Research on this area was sparse and further understanding of this field was motivated. All in all the potential benefits of this study outweighed the risks exposed to participants involved.

The protocol was approved by the Regional Ethics Review Board of Stockholm.

Ethical review board nr: 2012/1098-31/2 


\section{Results}

\section{Participants}

Participant characteristics are shown in table 1 for Stockholm Sleepy Brain 3 project with a total of 11 participant (6 male) and in table 2 for the pilot study Stockholm Sleepy Brain 2 with a total of 7 participants (4 male).

Table 1: Participant characteristics from the Stockholm Sleepy Brain 3 project, $(\mathrm{SD}=$ standard deviation).

\begin{tabular}{|l|c|c|}
\hline Variable & Mean & SD \\
\hline Age & 26 & 2.8 \\
\hline Height (cm) & 173 & 14 \\
\hline Weight (kg) & 69 & 14 \\
\hline $\begin{array}{l}\text { Interpersonal reactivity index, } \\
\text { subscale empathic concern }\end{array}$ & 13.6 & 4.0 \\
\hline State trait anxiety inventory & 47.6 & 3.7 \\
\hline $\begin{array}{l}\text { Positive_and negative affect } \\
\text { schedule_positive }\end{array}$ & 35.5 & 6.0 \\
\hline $\begin{array}{l}\text { Positive_and negative affect } \\
\text { schedule_negative }\end{array}$ & 19 & 4.8 \\
\hline $\begin{array}{l}\text { Hospital Anxiety and Depression } \\
\text { Scale_Depression }\end{array}$ & 2.6 & 0.9 \\
\hline Insomnia severity index & 4.5 & 3.0 \\
\hline
\end{tabular}

Table 2: Participant characteristics from the Stockholm Sleepy Brain 2 project, $(\mathrm{SD}=$ standard deviation).

\begin{tabular}{|l|c|c|}
\hline Variable & Mean & SD \\
\hline Age & 29 & 6 \\
\hline $\begin{array}{l}\text { Hospital Anxiety and Depression } \\
\text { Scale_Depression }\end{array}$ & 7.3 & 1.9 \\
\hline Insomnia severity index & 9.0 & 2.1 \\
\hline
\end{tabular}




\section{Unpleasantness ratings}

The main effect of stimulus type, sleep deprivation and instruction were investigated. Results are reported as effect estimates (rated unpleasantness) in original units with 95\% CI. Two significant effects were found. Firstly negative stimuli caused a significant increase in unpleasantness ratings $(13.4$ [11.6 - 15.2], $p<0.00001)$. Secondly the interaction negative stimuli*sleep deprivation caused a significant decrease in unpleasantness ratings $(-4.8[-8.34--1.25], p=0.0079)$. No other interactions were statistically significant. Instruction to downregulate emotional response did not cause lower rated unpleasantness (0.9 [-0.86 2.67], $p=0.32$ ). Sleep deprivation caused higher rated unpleasantness without significance (0.26 [-1.65 - 2.16], $p=0.79)$. Instruction downregulate*sleep deprivation caused a nonsignificant increase in unpleasantness ratings $(0.24$ [-3.29 - 3.78], $p=0.89)$. The results from the unpleasantness ratings are presented as boxplots in figure 3.
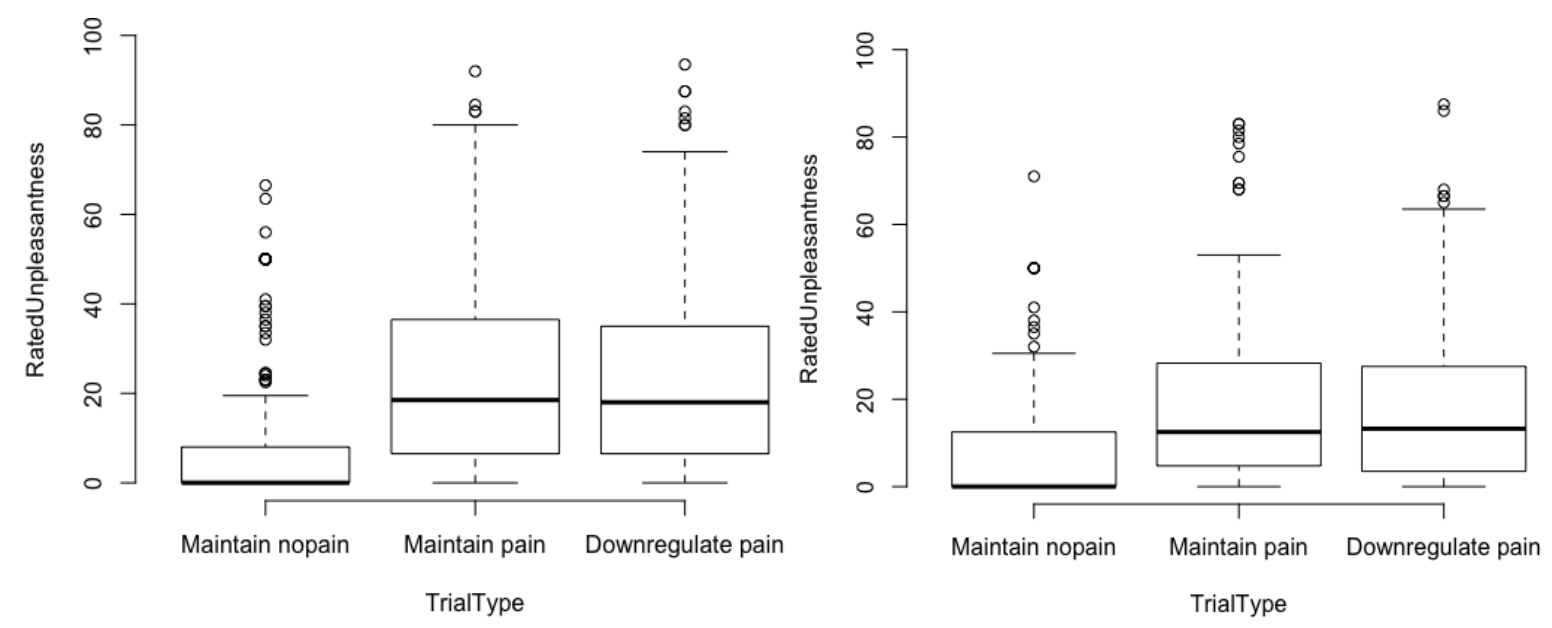

Figure 3: Means of rated unpleasantness based on each instruction and stimulus. To the left, full sleep results. To the right, sleep deprivation results.

Since the cursor for rated unpleasantness starts at the value of 50 the same analyses were done with ratings of 50 eliminated, assuming that ratings of 50 was accidental. Doing this we got similar results: Negative stimuli caused a significant increase in unpleasantness ratings (13.8 [12.1 - 15.4], $p<0.00001)$. Instruction to downregulate emotional response did not cause lower rated unpleasantness $(0.58[-1.11-2.27], p=0.49)$. Sleep deprivation caused higher rated unpleasantness with no significance $(0.69[-1.12-2.50], p=0.46)$. The interaction negative stimuli*sleep deprivation caused a significant decrease in unpleasantness ratings (-5.6 [-8.97$-2.20], p=0.0013)$. Instruction downregulate*sleep deprivation caused a non-significant increase in unpleasantness ratings $(0.84[-2.54-4.22], p=0.63)$ 


\section{fMRI results}

Regions of interest (ROI) are presented in figure 4 and figure 5.

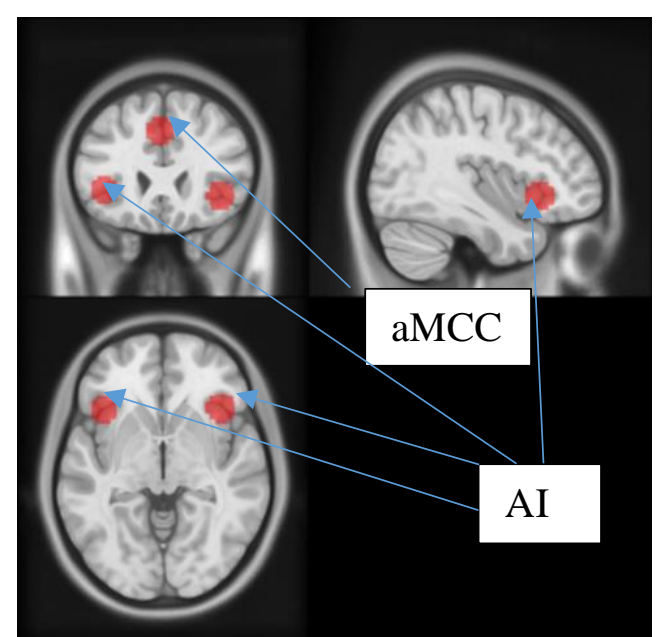

Figure 4: Regions of interest for empathy.

Anterior insula (AI) and anterior midcingulate cortex (aMCC) highlighted in red.

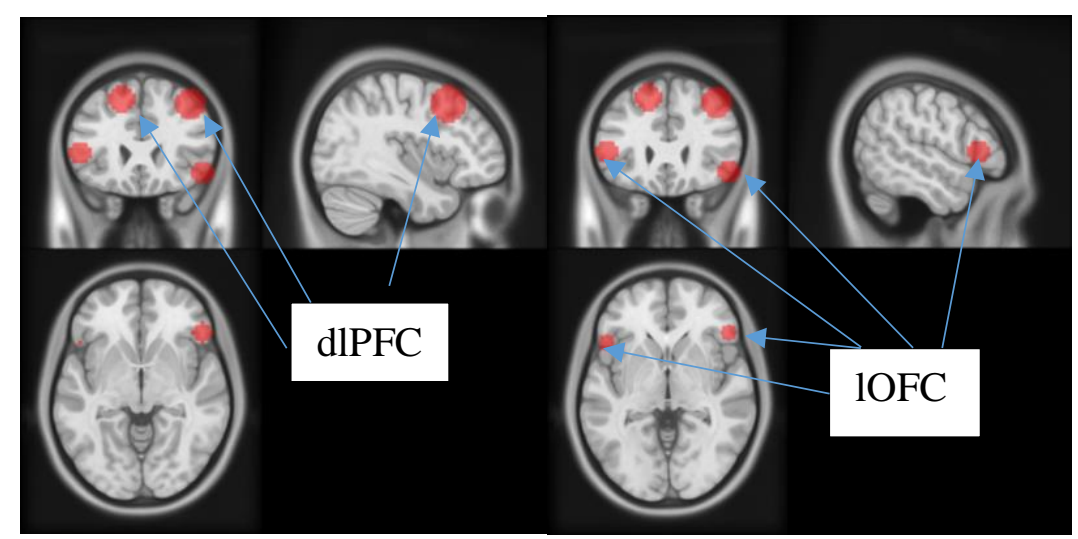

Figure 5: Regions of interest for emotional regulation.

Dorsolateral prefrontal cortex (dIPFC) highlighted and better seen in the left picture and lateral orbitofrontal cortex (lOFC) highlighted in the right picture. 
Main effects of stimulus type and instruction with respect to each ROI and the effect of sleep deprivation on all ROI were investigated. A significant activation of the aMCC was found when participants were exposed to pain stimuli. The effect on the left AI was not significant when participants were exposed to pain stimuli, however with a P-value close to $<0.05$. Instruction to downregulate did not significantly activate dlPFC or IOFC on either side. Sleep deprivation had no significant effect on any ROI with regard to each instruction. Table 3 and table 4 demonstrates the results.

Table 3: fMRI results 1st level analysis; main effect of Pain vs no pain or downregulate vs maintain in each ROI.

\begin{tabular}{|l|l|c|c|c|}
\hline ROI & Contrast & T-Value & CI - 95\% & P-value \\
\hline AI_L & Pain vs no pain & 0.86 & $-0.025-1.76$ & 0.056 \\
\hline AI_R & Pain vs no pain & 0.82 & $-0.25-1.88$ & 0.12 \\
\hline aMCC & Pain vs no pain & 2.52 & $0.17-2.18$ & 0.024 \\
\hline dIPFC_L & Regulate vs maintain & 0.076 & $-0.72-0.87$ & 0.84 \\
\hline dIPFC_R & Regulate vs maintain & 0.035 & $-0.90-0.97$ & 0.93 \\
\hline IOFC_L & Regulate vs maintain & 0.11 & $-0.72-0.94$ & 0.78 \\
\hline IOFC_R & Regulate vs maintain & 0.058 & $-0.61-0.73$ & 0.85 \\
\hline
\end{tabular}

Table 4: fMRI results 2nd level analysis; the effect of sleep deprivation vs full sleep in every ROI.

\begin{tabular}{|l|l|c|c|c|}
\hline ROI & Contrast & T-Value & CI - 95\% & $\boldsymbol{P}$-value \\
\hline AI_L & Pain vs no pain & 0.35 & $-0.93-1.63$ & 0.56 \\
\hline AI_R & Pain vs no pain & 0.32 & $-1.2-1.8$ & 0.65 \\
\hline aMCC & Pain vs no pain & -0.12 & $-1.31-1.05$ & 0.82 \\
\hline dIPFC_LL & Regulate vs maintain & -0.52 & $-1.58-0.55$ & 0.31 \\
\hline dIPFC_R & Regulate vs maintain & -0.54 & $-1.55-0.47$ & 0.27 \\
\hline IOFC_L & Regulate vs maintain & -0.025 & $-1.21-1.16$ & 0.96 \\
\hline IOFC_R & Regulate vs maintain & -0.42 & $-1.23-0.39$ & 0.29 \\
\hline
\end{tabular}




\section{Discussion}

\section{Recapitulation}

The aim of this study was to investigate how sleep deprivation affects empathy for pain and emotional regulation through self-rated unpleasantness scores and fMRI activity in the AI, aMCC, dlPFC and IOFC. A significant increase in self rated unpleasantness was seen when comparing negative stimuli to neutral stimuli, as expected. This confirms that experimental stimuli provoked feelings of unpleasantness among participants. A significant negative effect on unpleasantness ratings was seen when participants were exposed to pain stimuli after a night of total sleep deprivation irrespective of the instruction to downregulate one's emotional response, suggesting that sleep deprivation inhibited participants' empathic response. Activation of the left $\mathrm{AI}$ and the aMCC was found when participants were exposed to negative stimuli as expected, however the effect in the left AI was not statistically significant. This correlates well with the results from rated unpleasantness scores. No significant correlation was seen between instruction to downregulate one's emotional response to pictures of pain stimuli and activation of dlPFC and IOFC.

\section{In relation to previous studies}

\section{Ratings of unpleasantness}

The results in this study are similar to those presented by Guadagni et al (21) which demonstrated a significant negative effect on unpleasantness ratings after a night of total sleep deprivation. Guadagni et al (21) had 12 participants in each group and used a between group comparison in the analysis which might have caused a significant outcome due to differences between the groups or chance. However Guadagni et al (21) tried to correct for this in the analysis by using participants' pre scores as covariates when comparing post scores between groups. Similarly to this study Guadagni et al (21) used a sleep lab for the intervention night, Tamm et al (19) demonstrated similar results to this study and Guadagni et al (21), with borderline significance (0.07) after a night of partial sleep deprivation. The results are however not consistent with those presented in Tamm et al (16) in which no significant outcome could be seen when comparing unpleasantness scores between partial sleep deprivation and a night of full sleep. In both studies by Tamm et al (16) and Tamm et al (19) the total number of participants were higher, 71 and 44 respectively, but in these studies the intervention night consisted of partial sleep deprivation with 3 hours of sleep restriction. 
fMRI: Empathy

The activation of the AI and the aMCC when participants were exposed to negative stimuli are in line with previous meta analytic research (20) and the results presented by Tamm et al (19).

\section{fMRI: Emotional regulation}

No significant correlation was found between instruction to downregulate ones emotional response to pictures of pain stimuli and activation of dIPFC and IOFC which does not align with results presented by Tamm et al (16) nor with Ochsner et al (12) and Buhle et al (14) in their meta analyses where dIPFC and 1OFC among other areas in the prefrontal cortex emerge as key areas in emotional regulation. In the meta-analysis by Ochsner et al (12) a complexity regarding emotional reappraisal and its neuro-functional origin is presented. Firstly, as presented in the introduction, there are several theoretical ways of achieving emotional regulation. Namely situation modification, attentional deployment, emotional reappraisal and response modulation. Although participants were instructed to downregulate their emotional response in relation to negative stimuli in this study, they might have used for example attentional deployment rather than emotional reappraisal. In order to check for this we asked the participants after each session what regulation techniques they applied. Secondly as presented in Ochsner et al (12) it remains unstudied whether specific brain regions are activated when using different regulation techniques, so even if it could be determined that a particular techniques was used it might not guarantee an activation of the dlPFC or the 1OFC. However the sample size in this study was limited to 18 participants which might have contributed to less distinct findings in functional outcomes.

\section{fMRI: Sleep deprivation}

Studies investigating the effect of experimental sleep deprivation on functional aspects of emotional regulation are scarce. The results does align with previous research by Tamm et al (16) and Minkel et al (18) where no functional effects of sleep deprivation could be seen. No significant effect of sleep deprivation was found on activation of the AI or the aMCC which correlates with the results from Tamm et al (19). No other studies have investigated the effect of sleep deprivation on the functional aspects of empathic response. 


\section{Strengths and limitations}

One weakness in this study is a limited sample size and hence statistical power. 18 participants were included in the analyses, the limitation being that there was a set deadline for this project. This gives the results of this study limited validity. The Stockholm Sleepy Brain 3 project continues and will include analyses with higher numbers of participants later on. Furthermore only young participants were included and previous sleepy brain projects suggest differences in how older (50-65 years old) and younger (20-30 years old) participants respond to sleep loss and grade unpleasantness in response to unpleasant stimuli. These differences were not covered in this study since older participants showed having trouble with similar instructions in the previous sleepy brain experiments. Similarly, only healthy participants, where included which might affect the results and further limit the external validity of the study with respect to patient populations. One strength in this study was that it consisted of a well-controlled experiment by making sure that participants stayed awake during the intervention night using the sleep lab, by using a cross over design and applying the same time for experiments after intervention. Participants were extensively characterized. Moreover one could argue that including only younger (20-30 years old) participants is a strength since these participants are not as much affected by confounders to differences in empathic response and emotional regulation that could have evolved over time through life experiences.

\section{Significance}

A third of the general population is estimated to receive suboptimal sleep and the effect of sleep deprivation on emotional regulation and empathy (considered as important qualities in everyday human interactions) is not well studied so far. This study presents information on the possible negative effect of sleep deprivation and implies that sleep deprivation inhibits empathic response to others in painful situations. As presented in strengths and limitations, age has previously been speculated to have an impact on effects of sleep deprivation that are not yet known. Older participants were however excluded since they have previously demonstrated difficulties in following instructions. The results from this study may not be generalizable to groups with disorders or impairments of physical or psychological nature. It is however assumed in this study, that the physiological effects of sleep and sleep deprivation on empathy and emotional regulation are similar between healthy young individuals irrespective of gender, ethnicity and socio-economic background. 


\section{Future studies}

One aim in future research might be to investigate how or if different techniques of emotional regulation activate specific brain regions in order to better evaluate the effect on regions of interest in interventions studies. It could also be wise to instruct participants to apply a specific emotional regulation technique in future studies. Furthermore it would be good to combine a larger sample size with a distinct sleep deprivation regime, as is the plan in the ongoing Stockholm Sleepy Brain Project.

\section{Conclusion}

The experiment yielded higher self-rated unpleasantness and higher fMRI activity in aMCC in response to pain stimuli compared to non-pain stimuli, confirming the effectiveness of the experimental paradigm. According to the results of this study sleep deprivation has a negative effect on self-rated empathic response to others in painful situations, however without functional correlates in neural areas associated with empathy (AI and aMCC). No effects of sleep deprivation or instruction to downregulate emotional response could be seen either in self rated unpleasantness or functional measurements. The results indicate that future research might need either larger sample sizes or more specific regulation tasks in order to elucidate functional correlations between sleep deprivation, empathy for pain and emotional regulation.

\section{Contributions}

I took part in data acquisition and intervention nights throughout the semester together with co student Vivianne Jacobsson, research assistants Paolo D’Onofrio and Jimmy Hermansson and supervisor Gustav Nilsonne. MRI preprocessing was done by data curator Joe Wexler and Gustav Nilsonne. Statistical analysis was guided by Gustav Nilsonne. The whole report was written by me, the author, Poyan Karimi.

\section{Acknowledgements}

I would like to thank every member of the Stockholm Sleepy Brain Project, especially my supervisor Gustav Nilsonne for his guidance and patience and Jimmy Hermansson and Paolo D'Onofrio for their support and input. I also want to thank my coordinator Joy Roy for his valuable feedback. 


\section{Supervisor}

Gustav Nilsonne MD, $\mathrm{PhD}$, Researcher

Karolinska Institutet, Department of Clinical Neuroscience

Stockholm University, Stress Research Institute

Mail: gustav.nilsonne@ki.se 


\section{References}

1. Luyster FS, Strollo PJ, Zee PC, Walsh JK. Sleep: A Health Imperative. Sleep. 2012 Jun 1;35(6):727-34.

2. Rechtschaffen A, Bergmann BM. Sleep Deprivation in the Rat: An Update of the 1989 Paper. Sleep. 2002 Jan 1;25(1):18-24.

3. Shen X, Wu Y, Zhang D. Nighttime sleep duration, 24-hour sleep duration and risk of all-cause mortality among adults: a meta-analysis of prospective cohort studies. Sci Rep. 2016 Feb 22;6(1):1-8.

4. Liu Y. Prevalence of Healthy Sleep Duration among Adults - United States, 2014. MMWR Morb Mortal Wkly Rep [Internet]. 2016 [cited 2019 Dec 26];65. Available from: https://www.cdc.gov/mmwr/volumes/65/wr/mm6506a1.htm

5. Buxton OM, Marcelli E. Short and long sleep are positively associated with obesity, diabetes, hypertension, and cardiovascular disease among adults in the United States. Soc Sci Med 1982. 2010 Sep;71(5):1027-36.

6. Sutton EL. Psychiatric Disorders and Sleep Issues. Med Clin North Am. 2014 Sep $1 ; 98(5): 1123-43$.

7. Beattie L, Kyle SD, Espie CA, Biello SM. Social interactions, emotion and sleep: A systematic review and research agenda. Sleep Med Rev. 2015 Dec 1;24:83-100.

8. de Vignemont F, Singer T. The empathic brain: how, when and why? Trends Cogn Sci. 2006 Oct 1;10(10):435-41.

9. Hoffman ML. Empathy and moral development: Implications for caring and justice. New York, NY, US: Cambridge University Press; 2000. x, 331. (Empathy and moral development: Implications for caring and justice).

10. Lamm C, Decety J, Singer T. Meta-analytic evidence for common and distinct neural networks associated with directly experienced pain and empathy for pain. NeuroImage. 2011 Feb 1;54(3):2492-502.

11. Singer T, Seymour B, O’Doherty J, Kaube H, Dolan RJ, Frith CD. Empathy for pain involves the affective but not sensory components of pain. Science. 2004 Feb 20;303(5661):1157-62.

12. Ochsner KN, Silvers JA, Buhle JT. Functional imaging studies of emotion regulation: A synthetic review and evolving model of the cognitive control of emotion. Ann $\mathrm{N}$ Y Acad Sci. 2012 Mar;1251:E1-24.

13. Hu T, Zhang D, Wang J, Mistry R, Ran G, Wang X. Relation between Emotion 
Regulation and Mental Health: A Meta-Analysis Review. Psychol Rep. 2014 Apr $1 ; 114(2): 341-62$.

14. Buhle JT, Silvers JA, Wager TD, Lopez R, Onyemekwu C, Kober H, et al. Cognitive Reappraisal of Emotion: A Meta-Analysis of Human Neuroimaging Studies. Cereb Cortex. 2014 Nov 1;24(11):2981-90.

15. BOLD fMRI [Internet]. American Society of Functional Neuroradiology. [cited 2019 Sep 25]. Available from: https://www.asfnr.org/publication-library/bold-fmri/

16. Tamm Sandra, Nilsonne Gustav, Schwarz Johanna, Golkar Armita, Kecklund Göran, Petrovic Predrag, et al. Sleep restriction caused impaired emotional regulation without detectable brain activation changes - a functional magnetic resonance imaging study. R Soc Open Sci. 6(3):181704.

17. Yoo S-S, Gujar N, Hu P, Jolesz FA, Walker MP. The human emotional brain without sleep — a prefrontal amygdala disconnect. Curr Biol. 2007 Oct 23;17(20):R877-8.

18. Minkel JD, McNealy K, Gianaros PJ, Drabant EM, Gross JJ, Manuck SB, et al. Sleep quality and neural circuit function supporting emotion regulation. Biol Mood Anxiety Disord. 2012 Dec 7;2:22.

19. Tamm S, Nilsonne G, Schwarz J, Lamm C, Kecklund G, Petrovic P, et al. The effect of sleep restriction on empathy for pain: An fMRI study in younger and older adults. Sci Rep. 2017 Sep 25;7(1):1-14.

20. Lamm C, Decety J, Singer T. Meta-analytic evidence for common and distinct neural networks associated with directly experienced pain and empathy for pain. NeuroImage. 2011 Feb 1;54(3):2492-502.

21. Guadagni V, Burles F, Ferrara M, Iaria G. The effects of sleep deprivation on emotional empathy. J Sleep Res. 2014 Dec 1;23(6):657-63.

22. Davis MH. Measuring individual differences in empathy: Evidence for a multidimensional approach. J Pers Soc Psychol. 1983;44(1):113-26.

23. Sörman K, Nilsonne G, Howner K, Tamm S, Caman S, Wang H-X, et al. Reliability and Construct Validity of the Psychopathic Personality Inventory-Revised in a Swedish Non-Criminal Sample - A Multimethod Approach including Psychophysiological Correlates of Empathy for Pain. PloS One. 2016;11(6):e0156570.

24. Watson D, Anna L, Tellegen A. Development and Validation of Brief Measures of Positive and Negative Affect: The PANAS Scales. :8.

25. Spielberger CD. State-Trait Anxiety Inventory. In: Weiner IB, Craighead WE, editors. The Corsini Encyclopedia of Psychology [Internet]. Hoboken, NJ, USA: John Wiley \& 
Sons, Inc.; 2010 [cited 2019 Nov 19]. p. corpsy0943. Available from: http://doi.wiley.com/10.1002/9780470479216.corpsy0943

26. Jackson PL, Meltzoff AN, Decety J. How do we perceive the pain of others? A window into the neural processes involved in empathy. NeuroImage. 2005 Feb 1;24(3):771-9. 27. Decety J, Chen C, Harenski C, Kiehl KA. An fMRI study of affective perspective taking in individuals with psychopathy: imagining another in pain does not evoke empathy. Front Hum Neurosci [Internet]. 2013 [cited 2019 Oct 17];7. Available from: https://www.frontiersin.org/articles/10.3389/fnhum.2013.00489/full\#h2

28. Kaida K, Takahashi M, Åkerstedt T, Nakata A, Otsuka Y, Haratani T, et al. Validation of the Karolinska Sleepiness Scale against performance and EEG variables. Clin Neurophysiol Off J Int Fed Clin Neurophysiol. 2006 Aug 1;117:1574-81.

29. Jose Pinheiro and Douglas Bates and Saikat DebRoy and, Deepayan Sarkar and \{R Core Team\}. nlme: Linear and Nonlinear Mixed Effects Models [Internet]. 2019. Available from: https://CRAN.R-project.org/package=nlme

30. R Core Team (2017). R: A language and environment for statistical computing. [Internet]. Vienna, Austria.: R Foundation for Statistical Computing,; 2019. Available from: https://www.r-project.org/ 